\title{
Entre a marquise e a pista central: espaço para o tempo livre no Parque do Ibirapuera
}

\author{
Paulo Cezar Nunes Junior * \\ Sílvia Cristina Franco Amaral **
}

\begin{abstract}
Resumo: Este artigo tem como tema central a relação entre lazer e espaço urbano. Foram feitas trinta e oito visitas ao Parque do Ibirapuera (São Paulo) e, por meio do método de pesquisa antropológico, busca-se discutir o papel dos diferentes usos que um mesmo espaço pode conter para as práticas de lazer. As diversidades observadas na pista central e as subversões apresentadas pela marquise sugerem o mote para que estes e outros locais possam vir a ser espaço para o tempo livre.
\end{abstract}

Palavras-chave: Atividades de lazer. Áreas verdes. Antropologia cultural.

\section{INTRODUÇÃO}

Este artigo é fruto da dissertação de mestrado intitulada "Considerações sobre lazer e usos do espaço urbano no Parque do Ibirapuera". Trata-se de uma pesquisa qualitativa que lança mão do método de pesquisa antropológico para investigar os usos do Parque do Ibirapuera, em São Paulo, para o tempo livre. O foco foi dado na forma como os sujeitos, por meio de suas práticas de lazer, apropriam-se de alguns espaços específicos deste parque urbano, neste caso, a marquise e a pista central. Nosso esforço neste artigo é o de compilar os principais pontos discutidos nesta pesquisa, associando-os às reflexões travadas com o campo empírico.

O termo espaço é apreendido aqui como a soma de elementos materiais e imateriais, conjunto de fixos e fluxos (SANTOS, 1988) ${ }^{1}$ que se alteram constantemente. Certeau (1994) auxilia neste ponto quando

\footnotetext{
"Mestre em Educaçao Física pela Universidade Federal de Itajubá. Itajubá, MG, Brasil. E-mail: pcn_junior@yahoo.com.br

"Professora do Departamento de Educaçao Motora. Faculdade de Educaçao Física. Universidade Estadual de Campinas. Campinas, SP, Brasil. E-mail: scfa@fef.unicamp.br ${ }^{1}$ Segundo Santos (1988), se a definição dos fixos vem da qualidade e quantidade (ou densidade) técnicas que encerram, a definição dos fluxos deriva de sua qualidade e de seu peso políticos.
} 
estabelece o conceito de conjunto de móveis para as transformações contínuas travadas pela relação entre o sujeito e o entorno.

Lefebvre (1999) estabeleceu a categoria uso para tratar da interação entre o sujeito e a cidade, a qual pode ser relacionada ao conceito de espaço que trabalhamos aqui. $\mathrm{O}$ autor defende que esta relação deve ser dotada de valor de uso e não de valor de troca, e que as relações estabelecidas na realidade prático-sensível precisam ser compostas por sentido para que a apropriação ${ }^{2}$ do espaço possa ocorrer de forma significativa.

Entendemos que a possibilidade destes novos usos pode conduzir à transformação da realidade, neste caso específico, por meio das práticas de lazer. Neste sentido, o parque urbano pode ser um espaço propício para uma apropriação rumo ao tempo livre, de liberdade para a liberdade (MUNNÉ, 1980). Partindo das ideias deste autor, na combinação entre ações auto e heterocondicionadas, (MUNNÉ, 1980), ${ }^{3}$ o sujeito é capaz de ressignificar as suas ações a partir dos novos usos que faz do espaço.

Partindo destes referenciais, a temática propulsora deste estudo pode ser traduzida pela seguinte pergunta: qual a relação entre os usos feitos do espaço no Parque do Ibirapuera pelos sujeitos e o caminho para o tempo livre?

O objetivo, portanto, foi de entender a apropriação que os sujeitos fazem de alguns espaços do Parque Ibirapuera que se evidenciaram no decorrer do estudo como lugares onde os usos eram observados de forma mais rica e contundente. São eles a pista central e a marquise.

\section{PROPOSTA DE ANÁLISE E PRIMEIRAS APROXIMAÇÕES}

Como metodologia de trabalho, recorremos ao método de pesquisa antropológico para compreender os dados fornecidos pelo campo. Esta escolha ocorreu pela pertinência deste olhar microscópico (GEERTZ,

\footnotetext{
${ }^{2} \mathrm{Na}$ versão apresentada para a defesa do mestrado discutimos mais a fundo o conceito de apropriação, utilizando-nos principalmente dos textos de Codina (2007), Pol (1996) e Smolka (2006). ${ }^{3}$ De modo geral, o heterocondicionamento poderia ser definido pelas condições impostas pelo contexto social (as necessidades e as obrigações) ao indivíduo, enquanto o autocondicionamento seria a possibilidade de escolher condições segundo vontade própria, ou seja, segundo uma determinação interna. (VASQUEZ, 2008).
} 
1989) para os interesses deste trabalho. Seu caráter interpretativo auxilia na compreensão dos significados e no caminho até a relação necessidade/estratégia, percebendo como se estabelecem os usos na realidade prático-sensível (LEFEBVRE, 2006) do espaço urbano.

Ainda neste sentido, um ponto central esclarecido por Magnani (2002, p. 22) é que o importante para a elucidação deste método "não é a obsessão pelos detalhes [...], mas a atenção que lhes dá: em algum momento, os fragmentos podem arranjar-se num todo que oferece a pista para um novo entendimento".

Numa fase após as visitas ao campo e ao contato com a primeira parte destes fragmentos, desenvolveu-se uma pesquisa documental junto ao Arquivo Técnico do Parque do Ibirapuera, localizado na UMAPAZ - Universidade Livre do Meio Ambiente e da Cultura da Paz, onde pudemos ter acesso a documentos e reportagens referentes à história deste parque. ${ }^{4}$

A escolha do Parque do Ibirapuera para esta investigação ocorreu principalmente por dois motivos. Em primeiro lugar, é preciso considerar que o Parque do Ibirapuera é um dos parques mais frequentados da cidade de São Paulo (100 PARQUES, 2008). ${ }^{5}$ Em segundo lugar, salienta-se a diversidade de interesses que aparecem no seu uso, visto que o espaço oferece atrativos para os mais diversos públicos: crianças, corredores, esportistas, idosos, interessados em exposições de cultura e arte, entre outros públicos que o utilizaram no tempo em que o trabalho de campo ocorreu, de fevereiro a setembro de $2008^{6}$.

Ao todo, foram trinta e oito visitas. A decisão de escolha pelas observações apenas nos sábados, domingos e feriados foi feita em um momento posterior ao contato inicial com o campo, no final do

\footnotetext{
${ }^{4}$ Esclarecemos aqui que o contato com este arquivo só foi possível nesta fase da pesquisa, pois o mesmo encontrava-se em processo de mudança de sede e reorganização dos documentos, motivo pelo qual ele permaneceu fechado ao público até o mês de julho de 2008.

${ }^{5}$ O Programa 100 Parques para São Paulo é um projeto da Secretaria Municipal do Verde e do Meio Ambiente da prefeitura de São Paulo, lançado em janeiro de 2008. Desde então, levantou e reservou áreas para serem transformadas em parques em diversas regiões da cidade. Com ele, São Paulo ganhou 14 novos parques e outros 23 estão atualmente em diferentes fases de implantação.
} 
mês de março. Com frequência, em diferentes horários do dia, as visitas ocorreram sistematicamente até o mês de julho, com outras eventuais idas a campo nos meses de agosto e setembro.

O processo de aproximação com o Parque do Ibirapuera e a delimitação do campo ocorreram em três estágios diferentes. No primeiro deles, a intenção foi caminhar atentamente por todo o parque a fim de tomar contato com os lugares, com os sujeitos, com as sensações, com os fluxos, com os horários. Esta aproximação ocorreu paralela a um exercício de estranhar o familiar e se familiarizar com o estranho: as diferenças na concepção de tempo, a relação com a natureza, o encontro entre diferentes grupos, a dinâmica entre os usos, os horários e os dias.

Alguns sinais foram notados nesta fase inicial, porém procuramos ficar atentos, para que estes indícios não se constituíssem como normas, limitando-nos ao universo que começava a se apresentar para os horizontes desta pesquisa. Junto com eles, deixamos abertas as possibilidades para novos estímulos, novos temas que por ventura viessem a ocorrer no período de contato com o campo.

Apenas depois das primeiras visitas é que começamos a andar nos seus arredores. Pelo lado norte, é cortado pela Avenida Pedro Álvares Cabral, que se estende até o lado leste, onde se encontra com a Avenida 23 de Maio, entre outras ruas e cruzamentos de importantes vias da cidade. A condição de estar cercado por grande avenidas afasta o porque de possíveis proximidades com esta parte do seu perímetro.

Pelo lado sul e oeste, regiões que não estão voltadas para o centro da cidade e Avenida Paulista, as imediações caracterizam-se mais por ruas arborizadas, casas grandes e mansões, além de algumas praças e jardins. Em geral, o entorno do parque é composto por zonas residenciais, com exceção de um trecho que acompanha a Avenida República do Líbano, onde é possível encontrar pontos de serviço (lojas, papelarias, farmácia etc).

\footnotetext{
${ }^{6} \mathrm{~A}$ partir daqui, referiremo-nos somente aos dias e meses, uma vez que todo o trabalho de campo foi desenvolvido no decorrer do ano de 2008.
}

Movimento, Porto Alegre, v. 16, n. 02, p. 249-265, abril/junho de 2010. 
A localização do parque, ao lado de áreas habitadas pelas ditas elites ${ }^{7}$ da cidade - os bairros Jardim América e Jardim Paulista - e sua relativa centralidade e facilidade de acesso o transformaram em um importante parque de São Paulo, capaz de atrair milhares de usuários todos os dias para shows ao ar livre, exposições, práticas corporais, para o descanso, entre outros.

Com o desenrolar deste primeiro estágio, foram eleitos prioritariamente os finais de semana para as idas ao Parque do Ibirapuera, intercalados entre os períodos matutino e vespertino. Até o segundo estágio da investigação, aconteceram visitas em diferentes dias da semana e ocasionalmente à noite (duas visitas). ${ }^{8} \mathrm{~A}$ escolha pelos finais de semana ocorreu por tratar-se dos dias em que as visitas ao Parque do Ibirapuera facilmente multiplicavam-se com relação à frequência nos demais dias da semana, ${ }^{9}$ fato que poderia acarretar maiores possibilidades de novos usos.

A partir disso, delineou-se o segundo momento do contato com o Parque do Ibirapuera. Neste estágio, o esforço ocorreu no sentido de escolher trechos que fossem mais significativos para sustentar ou refutar as construções feitas sobre a temática da pesquisa. Depois de 14 visitas aos playgrounds, à pista de cooper, às quadras, à marquise, ao bicicletário, ${ }^{10}$ à pista central, aos museus e espaços de exposição, aos lagos, ao viveiro de mudas, entre outros, alguns destes espaços mostraram-se mais pertinentes para fomentar os principais

\footnotetext{
${ }^{7} \mathrm{O}$ contato com o campo nos seis meses de trabalho nos cederam pistas em relação ao poder aquisitivo do público que mora próximo ao parque do Ibirapuera, embora em nenhum momento eu tenha recorrido a censos e outras fontes de informações. O preço dos aluguéis e o anúncio da venda de imóveis em ruas e avenidas próximas eram muito altos, com valores que podem ser custeados apenas por pessoas endinheiradas. As lojas e pontos de comércio da Avenida do Líbano também vendem produtos com preços acima do comumente encontrado. Pudemos comprovar isso ao pagar algumas fotocópias no dia $1^{\circ}$ de junho: o triplo do que geralmente se cobra para este tipo de serviço.

${ }^{8}$ Apesar do funcionamento noturno diário do Parque do Ibirapuera, optamos por limitar as observações apenas durante o dia.

${ }^{9}$ Segundo informações de um panfleto intitulado "Guia do Parque Ibirapuera", distribuído pela administração, a freqüência média de usuários por dia sobe de 20 mil de segunda a sexta feira para 70 mil no sábado e 130 mil usuários no domingo.

${ }^{10}$ Consideramos conveniente explicar como funciona o bicicletário do Parque do Ibirapuera. Trata-se de um setor de aluguéis de bicicletas, onde existem duas pequenas empresas prestadoras deste serviço. Pagando o valor de cinco reais, o locatário aluga a bicicleta por uma hora. Aberto apenas nos finais de semana e feriados, o bicicletário apresenta intenso fluxo de pessoas o dia todo, apesar da quantia cobrada.
} 
pontos da discussão pretendida nesta pesquisa, principalmente a marquise e a pista central, por congregarem diferentes possibilidades de usos em um mesmo lugar.

Com esse primeiro contato, foi possível notar que nos museus e espaços destinados às exposições praticavam-se usos que destoavam daqueles observados em outras áreas do parque. No que concerne à noção de tempo e às supostas funções do lazer no parque urbano, estes lugares eram vivenciados como espaços anexos ao Parque do Ibirapuera. Na Natural Tech - Feira Internacional de Produtos Naturais, Alimentação Saudável e Medicina Complementar, que ocorreu no final de semana do dia 22 de abril, as dezenas de stands montados recebiam um público que supostamente frequentava o parque naquele dia com o objetivo principal de visita ao evento.

Fato semelhante ocorria com algumas exposições, além do que o lazer, nestes espaços, apresentava-se com especificidades que a discussão travada por esta pesquisa não daria conta de responder (as relações com a arte, por exemplo). Por isso, tomamos a decisão de nos afastar desses espaços e centrar nossas observações em outros.

A escolha pela marquise e pela pista central ocorreu devido às suas características de versatilidade, o que garantia diversidade no conjunto dos usos que podem ali ser desenvolvidos, tornando-os locus interessante para uma análise em torno da apropriação. Na marquise, foram diversos os usos desenvolvidos por parte de skatistas, patinadores e ciclistas de rua, que dividiam este espaço com orquestras (no dia 12 de abril), apresentação de coral (no dia 13 de abril) e demonstrações de dança (dia 6 de julho). Ao caminhar pela pista central, era possível tanto o encontro com corredores, ciclistas e patinadores quanto o encontro com artistas de rua (8 junho e 25 de maio) e feiras de saúde em seus arredores, como uma que ocorre ocasionalmente em um ponto armado próximo ao Pavilhão Japonês, como no dia 5 de julho.

No terceiro momento, aconteceu uma aproximação mais microscópica com o campo: as quantidades e os fluxos observados, as normas que se repetiam no uso da pista, os picos de frequência ao longo do dia, a chuva ocasional, os eventos pontuais. 
Nesta fase, a impregnação pelos estímulos visuais e elementos que nos pareciam significativos propiciou contatos com os sujeitos, ocorridos de forma não linear. As perguntas e diálogos ocasionais com alguns deles eram intercaladas por horas de observação frente às cenas que se passavam nestes espaços.

Alguns dos pontos mais significativos desses meses de pesquisa de campo serão apresentados a seguir, de modo a discutir a possibilidade do Parque do Ibirapuera vir a ser um espaço para o tempo livre, neste caso, pelos usos feitos da marquise e da pista central.

\section{A PRODUÇÃO DO ESPAÇO: DIVERSIDADE E SUBVERSÃO}

No período de visitas ao Parque do Ibirapuera, os diversos usos do espaço observados no movimento de fixos e fluxos (SANTOS, 1988) revelaram duas ${ }^{11}$ grandes categorias para serem discutidas: as diversidades reveladas pela pista central e as subversões na marquise. Vamos nos deter sobre cada uma delas, a partir das impressões do contato com o campo de pesquisa.

\section{PISTA CENTRAL: REVELANDO AS DIVERSIDADES}

Denominamos aqui de pista central o espaço que se apresenta no Parque do Ibirapuera por meio de um trajeto contínuo que liga suas principais áreas. Destinada principalmente às práticas de corrida e de ciclismo, ${ }^{12} \mathrm{o}$ asfalto e as marcações da ciclovia conferem oportunidades para que pedestres e bicicletas transitem sem grandes problemas.

Um dos pontos que mais chamou a atenção na observação da pista foi notar a diversidade do público que a frequenta. Sujeitos desfilam com estilo esportivo, em oposição aos ditos marginais: o grupo de jovens da periferia, os garotos com suas bikes de rua.

\footnotetext{
${ }^{11}$ Há ainda uma terceira categoria presente neste estudo, o "oásis" e o papel do Parque do lbirapuera de freio à contração do espaço urbano e da vida na cidade. Ler NUNES JUNIOR (2009).

${ }^{12}$ Cabe ainda colocar que normalmente podem ser observados na pista patinadores, skatistas, além de outras formas mais "raras" de uso (monocliclos e patinetes, por exemplo).
} 
Também merece destaque a presença dos cachorros e seus acompanhantes durante todo o dia. Labradores, pitbulls, pastores alemães e outras raças, sempre com guias e coleiras. Poodles com pelos bem aparados e lacinhos", para as fêmeas, fox paulistinha e bacês geralmente vestidos para o fim de semana.

Para seus donos, o Parque do Ibirapuera compõe-se também por passarela. Além de ser um local onde o animal é levado para passear, funciona como corredor de apresentação. Sobre esta ideia, um fato que normalmente ocorre em um gramado merece ser citado. Observamos nos dias 18 de maio e 5 de julho que ali ocorre um encontro de cachorros de várias raças. É onde os donos levam os animais para "brincar" com outros de mesma raça ou de raças diferentes. Conforme observado em vários fins de semana, este encontro sugere a troca de contatos, outros programas em conjunto, além da possibilidade de cruzamento dos animais e venda de filhotes.

Para o caso da passarela, é possível dizer que o cachorro transmuta-se em uma espécie de arquétipo do discurso proferido pelo seu dono. Continuidade do conjunto de significantes engendrados por seu acompanhante no uso do parque. Ao observá-los, era inevitável a lembrança da etnografia de Geertz (1989) sobre a briga de galos balinesa. Nesta, os animais funcionam como metáfora para a masculinidade, para o poder de mostrar-se competitivos na disputa com outro de força equivalente.

No Parque do Ibirapuera, os cachorros representam partes constitutivas de seu dono, como os poodles, a esposa delicada; o whippet, esguio e veloz e seu dono corredor; o tônus do pitbull em semelhança com o corpo de seu dono, atlético e musculoso, metamorfoseado em animal, com face sisuda. Além do cão, há outros meios pelos quais os sujeitos se mostram. Ou pela exibição evidente do corpo: o rapaz com o peitoral definido, a lânguida beleza da moça, o idoso entrando em forma, ou por outros incrementos e

\footnotetext{
${ }^{13}$ No início das tardes de domingo, um sujeito chegava à pista do Parque do Ibirapuera com uma bicicleta cor-de-rosa, de modelo antigo, com piranhas (aquelas presilhas utilizadas para prender o cabelo) cobrindo-a toda, desde o quadro até as raias. Temos anotadas no caderno de campo três visitas deste sujeito ao parque, nos dias 19 e 26 de abril e no dia 3 de maio.
} 
meios de dar continuidade ao corpo na enunciação de discursos: a bicicleta cheia de piranhas'coloridas ${ }^{13}$, as diferentes bikes de corrida, os skates.

No dia 5 de abril, ocorreu um fato que pode elucidar o porquê da eleição da pista central como um lugar importante, onde as diversidades revelam-se, além dos demais lugares já trabalhados. Duas senhoras, aparentemente de classe alta, caminham desinteressadamente pela pista quando são avisadas abruptamente por um assovio da passagem de um pelotão de bicicletas na pista. Elas atendem ao pedido a contra gosto e cedem caminho enquanto reclamam em baixo tom sobre o ocorrido. Um dos garotos escuta o comentário e automaticamente revida em tom áspero: "só podia ser rico mesmo". Este fato corriqueiro concede a impressão que desejamos apresentar quando afirmamos que a pista central é sinônimo de diversidade.

As várias propensões de usos garantem a versatilidade do espaço e a flexibilidade de seus fluxos. Diferentemente do que pode acontecer em espaços de lazer homogêneos, como geralmente ocorre com os conjuntos habitacionais, na pista central, a diversidade é causada tanto pela heterogeneidade das métricas (LÉVY, 1999), ou seja, o passeio a pé, a corrida, as bicicletas, o patins, o skate, quanto pelo encontro de públicos e pedaços que podem compartilhar de suas diferenças do mesmo espaço, pessoas da periferia e do centro, o marginal e o playboy, os idosos e as crianças, entre outros.

Por esses elementos, grosso modo, deduz-se que o espaço da pista central recebe diferentes usos durante os dias convencionais de trabalho e aos finais de semana. A riqueza do contato com a pista, a partir destas questões estabelecidas e dos fatos observados principalmente no sábado, no domingo e nos feriados é que garantem a ideia de que há possibilidades de saídas do sistema por meio da apropriação, da imprevisibilidade de atuação dos cotidianos.

Tensionados pelo auto e heterocondicionamento, o sujeito é colocado o tempo todo em situações nas quais ele pode vivenciar o tempo livre (MUNNÉ, 1980). No Parque do Ibirapuera, essas situações deverão acontecer por meio das práticas de lazer, em um local e tempo específicos da pista central, com todas as imprevisibilidades e possibilidades que estes usos podem conter. 


\section{USOS PARA O ESPAÇO LISO: A SUBVERSÃO NA MARQUISE}

Próximo à pista central, projeta-se a famosa marquise do Parque do Ibirapuera, interligando as entradas do Museu de Arte Moderna, do Museu Afro e do Auditório Ibirapuera. Trata-se de uma área coberta, com grandes vãos sustentados por colunas e piso simples, condição que fornece à marquise a função de espaço versátil para os mais diversos usos.

No período do trabalho de campo, foi possível observar inúmeras maneiras de utilização deste espaço: apresentação de orquestra sinfônica, na exposição do Exército Brasileiro, no dia 12 de abril; apresentação de coral de idosos, durante evento no dia 13 de abril; posto de arrecadação de material reciclável, também no dia 13 de abril; postos de vacinação infantil, no dia 17 de maio; apresentação de street dance, no dia 6 de julho, entre outros. Cada um desses pequenos eventos aconteceu com sujeitos diferentes, de grupos distintos e com intenções próprias. Esta diversidade compõe a marquise com marcas interessantes, dotando-a de distintos significados a partir dos usos feitos desse espaço.

Entretanto, a grande referência de utilização deste espaço ocorre por parte dos esportes e das manobras de rua. Embalados, às vezes, por um som ambiente, uma espécie de break; a seu tempo, dezenas de bicicletas, patins, skates e outros equipamentos similares ganham o espaço da marquise aos finais de semana, notadamente no sábado e no domingo à tarde. No período das observações, frequentaram o espaço da marquise invariavelmente, com exceção dos dias de chuva, quando o movimento no parque caía consideravelmente.

Tomada principalmente por jovens e adolescentes nos finais de semana (em sua grande maioria do sexo masculino), a marquise abriga sujeitos oriundos de diferentes bairros da região metropolitana de São Paulo, conforme pudemos constatar pelos breves comentários ou por pequenas interlocuções travadas com eles enquanto permanecíamos nos arredores da marquise, como demonstram as seguintes falas, tomadas, respectivamente, nos dias 15 de junho e 17 de agosto: "vamu logo, senão a gente vai chegar em Embu só às dez 
da noite" ou "lá na ZL ${ }^{14}$ não tem essa história de ficar tirando com a cara do outro não".

A diferença de uso da marquise entre o fim de semana e os dias convencionais de trabalho é marcante. De segunda-feira a sexta-feira, é possível observar neste espaço apenas caminhões de limpeza, além da presença de esporádicos praticantes de ginásticas sob a orientação de um personal trainner, como observei nos dias 11 e 18 de março. Geralmente em grupos, os sujeitos presentes nos finais de semana usualmente portam uma mochila com lanche para passar o dia no parque e se vestem com estilo específico, de boné, camisetas e calças largas, com a cueca à mostra. Os tênis também são de estilo próprio, de desenho arredondado, com cadarços coloridos e solas largas, o que facilita as frenagens que sucedem as manobras e os movimentos mais rápidos.

Entre os grupos que frequentam este espaço, o dos ciclistas é o mais significativo. Em maior número, mostram-se de forma exibicionista em meio a giros arriscados e pequenas quedas acidentais, com bicicletas cheias de detalhes para a prática de determinados movimentos. Conforme apresentado pelas observações, o selim rebaixado e o suporte nos pneus dianteiro e traseiro podem indicar em qualquer região do parque que aquele sujeito frequenta a marquise.

Em direção oposta à área das bicicletas, o grupo de patins mescla diferentes sexos e idades. Os patinadores geralmente montam circuitos específicos, formas de locomoção, com zigue-zagues e volteios próprios de sua prática. Outro grupo de destaque da marquise é o dos skatistas, que apresenta maior similaridade de trajes com o grupo das bicicletas.

Diferentemente de pistas próprias ou outros locais destinados à prática destas modalidades de rua, na marquise do Parque do Ibirapuera os usos, tanto pelas bicicletas quanto pelos patins e pelo skate, ocorrem apenas em um vão livre sem nenhum equipamento específico para estas práticas, como corrimãos, rampas ou pequenas plataformas para saltos. ${ }^{14}$ Corruptela para "Zona Leste", região da periferia da cidade que compreende bairros como
Penha e Guaianazes. 
Durante as visitas ao campo, foi observada a utilização de alguns materiais improvisados para manobras específicas: caixas de papelão, garrafas descartáveis, entre outros, exemplificando alguns dos apetrechos utilizados para dar usos ao espaço.

Embora possa parecer estranho o fato deste espaço desprovido de rampas e incrementos para saltos ser tão procurado por parte destes grupos, esta situação explica-se pelo fato de ser um ponto de encontro. A marquise tem notoriedade para estes sujeitos na medida em que consegue reunir centenas de jovens com suas gírias, seus trejeitos, especificidades próprias de suas turmas e de seus bairros. Nas observações feitas no dia 25 de maio, notamos as similaridades das roupas dos ciclistas: o boné virado para trás, a calça larga e as gírias utilizadas. Ao mesmo tempo, um grupo de skatistas faz uma roda e começa a comer os lanches, o refrigerante de marca econômica e o pacote de biscoitos são quase os mesmos para todos.

Este conjunto de significados (GEERTZ, 1989) liga a marquise a estes grupos, a qual revela-se um espaço de usos para o desenvolvimento das práticas e de uma cultura vivenciada geralmente em guetos ou nas ruas de zonas periféricas da cidade. Ao mostrar suas manobras, na verdade cada um deles está fazendo o exercício de marcação de territórios, aprendendo não só as técnicas destas práticas, como também as técnicas de pertencimento ao grupo. Por trás dos gestos expressados por cada jovem, encontram-se performances de vida que, subversivamente, fazem uso da marquise para a manutenção de sua identidade na produção do espaço.

O espaço da marquise não é liso (GUATARRI, 1985) ${ }^{15}$. Se, a princípio, a homogeneidade causada pelo piso de cimento batido, pela simetria das colunas brancas e pelo teto com luzes igualmente espaçadas dá a aparência uniforme ao lugar, o conjunto composto pelos sujeitos e seus usos reverte esta situação. Cada grupo apresenta especificidades, estratégias e astúcias (CERTEAU, 1994) próprias para ocupar os fixos (SANTOS, 1988), conforme destacam as descrições aqui apresentadas. Os sujeitos elegem determinados lugares na marquise para permanecerem durante o dia. Recostados em alguma coluna, próximos aos playgrounds ou no corredor mais 
próximo ao Museu Afro, estabelecem marcas para os espaços que ocupam: bicicletas deitadas no chão, mochilas apoiadas nas paredes, aparelho de som ligado.

A parede branca na região dos sanitários é literalmente marcada pelo uso das bicicletas e dos skates. No dia 22 de setembro, acompanho as tentativas de um garoto para a realização de uma manobra. Depois da fase de aceleração, um salto é seguido do contato com a parede para uma posterior aterrisagem, a qual dá origem à aceleração para um novo ciclo. Ela fica toda suja por estas e outras tentativas feitas, substituindo a homogeneidade do branco pelos traços escuros de borracha das rodas de bicicletas e skates. Cada gesto observado é próprio de seu executor e dota a marquise de determinados usos. Elementos diversos, marcadores de sentido para o espaço que a distanciam da condição primeira de espaço liso (GUATARRI, 1985).

Um ponto que chamou a atenção nos arredores da marquise foi a presença de vigilantes em maior número em comparação com outras áreas do parque. Este fato indica resistência à cultura e à efervescência construída na rua, como notamos nas tensões observadas entre os policiais e os frequentadores da marquise. Sábado, dia 14 de junho, no início da tarde, um caminhão pipa atravessa a marquise para a limpeza dos banheiros. Enquanto desenvolve seu trajeto lento pelo vão livre, um grupo de adolescentes se prepara para pegar uma carona com ele. Ao notar a movimentação, os policiais acionam reforços para conter a ação, mas não têm tempo para se organizar. Neste momento, dezenas de adolescentes já estão pendurados no caminhão, satisfeitos pela travessura causada.

Estas passagens narram fatos ocorridos no período de visitas ao Parque do Ibirapuera. As relação destes sujeitos com a marquise e com a pista central mostraram sinais de subversão e de diversidade na dinâmica da produção do espaço. Fatos como estes podem ajudar a pensar sobre a dinâmica dos parques no desenvolvimento das cidades, partindo das práticas de lazer no espaço urbano. Resta saber qual é o poder que tais experiências podem conter para a transformação da realidade e a conduta ao tempo livre (MUNNÉ, 1980). 


\section{POR UM ESPAÇO PARA O TEMPO LIVRE}

Como expressão que busca dar avanço ao tema tratado nesta pesquisa, sugerimos que a resultante das forças que participam da formação do espaço urbano e da constituição do lazer na realidade observada seja construída na direção do espaço para o tempo livre.

Grifamos esta expressão porque defendemos que ela é uma forma de traduzir a resposta para as perguntas sugeridas no início deste texto. Salientamos ainda a utilização do termo espaço no singular. Trata-se de conceber uma ideia abstrata, conforme o conceito de Santos (1996). Quando fala-se em espaços, fica a impressão de que essas abstrações já aparecem de maneira mais decantada, materializados em praças e parques, por exemplo.

Neste conceito, fica implícito que nos locais onde o lazer possa ocorrer, as atividades tenderão a tornar o ser humano livre, em uma relação com a cidade a partir do valor de uso (LEFEBVRE, 2006). Além disso, nas experiências dos sujeitos devem estar implícitos indícios para a crítica constante dos dados materiais, como o encontro dos diferentes públicos na pista central. Lugares como estes observados no Parque do Ibirapuera devem ser tomados a partir de suas possibilidades utópicas, em que os espaços e equipamentos de lazer apresentam vários pontos que podem servir à conduta para $\mathrm{o}$ tempo livre.

Pelo conceito de tempo livre empregado por Munné (1980), o caminho a ser seguido operaria de modo à liberação compensadora do heterocondicionamento, satisfazendo as necessidades reais de liberdade e estabelecendo caminhos para que tal situação ocorra. Neste ínterim, tratar dos usos do espaço se faz importante na medida em que eles pressupõem sua apreensão a partir de atividades nas quais pode predominar o caminho para a liberdade. As relações entre o sujeito e o local produziriam novas apropriações, pelas quais o tempo livre pode acontecer, pela ação autêntica entre sujeito e espaço e não apenas pela sobrecompensação ao trabalho.

Assim como o tempo livre não necessariamente precisa ser tempo de lazer, o espaço para o tempo livre também não é, a priori, 
um espaço de lazer. Liga-se a esta afirmação o fato de que nos espaços de lazer hoje disponíveis, como é o caso do Ibirapuera, existem mais possibilidades de autocondicionamento. Primeiro, porque a intencionalidade de uso do parque já implica o exercício de liberdade (passar o domingo com a família, namorar etc.) Segundo, porque, além disso, há uma folga tanto na contração do tempo (pela noção do tempo liberado do trabalho, pela vivência não parcelada do dia) quanto pela contração do espaço (não há carros nem outros meios de transporte que possam encurtá-lo). Neste sentido, sugerimos um deslocamento do termo espaços de lazer para a expressão espaço para o tempo livre.

Com isso, dizemos, a essa altura, que o Parque do Ibirapuera apresentou nesses meses de campo inúmeras possibilidades para o tempo livre. A inversão de sentido aqui tem duplo papel: além de atuar na desconstrução de algumas oposições criadas nos estudos do lazer (lazer/trabalho, tempo livre/tempo de trabalho etc.), encaminha as questões dos usos e da apropriação do espaço como medidas transformadoras, colocando o sujeito em um papel ativo de construção da realidade, a partir do poder contido nos usos observados.

Pela atuação intermitente na conformação destas cadeias de signifiados, é possível ponderar que o espaço não é um pano de fundo neutro. Ele não é apenas um reflexo da sociedade nem um fato social apenas, mas um condicionante condicionado, tal como as demais estruturas sociais, que é constituído pelo movimento dos fatos ao mesmo tempo em que o influencia (CERTEAU, 1994).

Por isso mesmo, é preciso colocar o olhar próximo à realidade, no esforço de compreender qual a relação estabelecida entre o sujeito e o espaço do qual ele participa. A partir do entendimento do lazer como construção que surge da contradição presente na vida cotidiana e nestes usos, é possível estabelecer relações de suas atividades com o espaço urbano, nó conceitual que traz consigo as possibilidades de transformação a partir das passagens narradas neste trabalho. Pelo olhar sobre o uso de espaços como a marquise e a pista central, é possível vislumbrar a construção de espaço para o tempo livre, para a liberdade, nas práticas de lazer e nas demais esferas da vida. 


Between the marquise and the central track.
Space for free time in the Ibirapuera Park.
Abstract: This paper has as central topic the relation
between leisure and urban space. There have been
made thirty eight visits to the lbirapuera Park (São Paulo).
Through the method of anthropological research, we
tried to understand the role of the differents uses that
the same space can contain for the leisure pratices.
The differences observed in the central track and the
subversion presented by the marquise suggest the
motto for these and others places to be able to become
space for free time.
Keywords: Leisure activities. Green areas. Cultural
Anthropology.

Entre la marquise y la pista central. Espacio para
el tiempo libre en el Parque del Ibirapuera
Resúmen: Este artículo tiene como tema céntrico la
relación entre ocio y espacio urbano. Fueron hechas
treinta y ocho visitas al Parque del lbirapuera (São Pau-
lo), y, por medio del método de investigación antropoló-
gico, se busca discutir el papel de los diferentes usos
que un mismo espacio puede contener para las prácticas
de ocio. Las diversidades observadas en la pista cen-
tral y la subversión presentada por la marquise sugieren
el mote para que estos y otros locales puedan venir a
ser espacio para el tiempo libre.
Palabras clave: Actividades recreativas. Áreas ver-
des. Antropologia cultural.

\section{REFERÊNCIAS}

CERTEAU, M. A invenção do cotidiano: artes de fazer. Tradução Ephraim Ferreira Alves. Petrópolis: Vozes, 1994.

CODINA, N. Entre el ocio, el turismo y el consumo. el tiempo y la apropiación del tiempo. In: MARTINEZ, J. R. (org.). Perspectivas y retrospectivas de la Psicología Social en los albores del siglo XXI . Madrid: Biblioteca Nueva, p. 205-214, 2007.

GEERTZ, C. A interpretação das culturas. Rio de Janeiro: Guanabara Koogan, 1989.

GUATARRI, F. Espaço e poder: a criação de territórios na cidade. Espaço e Debates, São Paulo, n.6, p.109-121, 1985.

Movimento, Porto Alegre, v. 16, n. 02, p. 249-265, abril/junho de 2010. 
Entre a marquise e a pista central: espaço para o tempo livre...

LEFEBVRE, H. O direito à cidade. Tradução de Rubens Eduardo Frias. São Paulo: Centauro, 2006.

A revolução urbana. Belo Horizonte: Editora UFMG, 1999.

LÉVY, J. Le Tournant Geografique. Belin, Paris, 1999.

MAGNANI, J. G. C. De perto e de dentro: notas para uma etnografia urbana. Revista Brasileira de Ciências Sociais, São Paulo, v. 17, n. 49, p.11-29, 2002.

MUNNÉ, F. Psicossociologia del Tiempo libre: un enfoque crítico. México: Trillas, 1980.

NUNES JUNIOR, P. C. Espaço para o tempo livre: considerações sobre lazer e apropriação do espaço urbano no Parque do Ibirapuera. 2009. 91 f Dissertação (Mestrado) Manuscrito não publicado - Faculdade de Educação Física, Unicamp, Campinas, 2009.

POL, E. La apropiación del espacio. In: İÑíGUEZ, L.; POL, E. (coord.) Apropiación, Cognición y Representación Ambiental. Monografías PsicoSocioAmbientales. Barcelona: PUB, 1996.

SANTOS, M. A natureza do espaço. São Paulo: Hucitec, 1996.

O espaço do cidadão. São Paulo: Edusp, 1988.

SÃO PAULO. SECRETARIAMUNICIPAL DO VERDE E DO MEIOAMBIENTE. 100 Parques... Disponível em: <http://www9.prefeitura.sp.gov.br/sitesvma/100_parques/ regiao/sul/index.php?p=46> Acesso em 22 ago. 2008.

SMOLKA, A. L. B. O (im)próprio e o (im)pertinente na apropriação das práticas sociais. Caderno Cedes, Campinas, v.20, n.50, p. 26-40, abr. 2000. Disponível em < http://www.scielo.br/pdf/ccedes/v20n50/a03v2050.pdf > Acesso em 18 jul. 2006.

VASQUES, N. A. Lazer e educação: estudo bibliográfico desta relação. 2008. 53f. Monografía (Licenciatura) Curso de Pedagogia, Faculdade de Educação. Unicamp, Campinas, 2008.

Financiamento: CAPES

Movimento, Porto Alegre, v. 16, n. 02, p. 249-265, abril/junho de 2010. 